\title{
GEOGRAFSKO VREDNOTENJE DEGRADIRANIH OBMOČIJ V IZBRANIH STATISTIČNIH REGIJAH
}

\author{
Anja Cvahte, Luka Snoj \\ Oddelek za geografijo, Filozofska fakulteta Univerze v Ljubljani \\ Aškerčeva 2, SI-I000 Ljubljana \\ e-mail: anjacvahte@gmail.com; snojlu@gmail.com \\ Pregledni znanstveni članek \\ COBISS 1.02
}

\section{Izvleček}

Degradirana območja so neustrezno izkoriščeni deli pokrajine, ki s primerno ureditvijo in upravljanjem predstavljajo potencial za trajnostno rabo. Enotna, celovita in ažurna evidenca degradiranih območij je le začetna faza pri doseganju tega cilja. V prispevku je predstavljena identifikacija, inventarizacija ter geografsko vrednotenje degradiranih območij v Gorenjski, Osrednjeslovenski, Zasavski in Spodnjeposavski statistični regiji ter v statistični regiji Jugovzhodna Slovenija.

Ključne besede: degradirana območja, trajnostni razvoj, varovana območja, pokrajinskoekološki tipi

\section{GEOGRAPHICAL EVALUATION OF BROWNFIELDS IN SELECTED STATISTICAL REGIONS}

\begin{abstract}
Brownfields are inadequately exploited parts of landscape which could, with proper organization and management, present a potential for sustainable use. A uniform, complete and up-to-date record of brownfields is the initial phase in achieving this goal. The paper presents identification, inventory and geographical evaluation of brownfields in selected statistical regions of Gorenjska, Osrednjeslovenska, Spodnjeposavska, Zasavska and Jugovzhodna Slovenija.
\end{abstract}

Key words: brownfields, sustainable development, protected areas, landscape ecology 


\section{UVOD}

V strokovni literaturi ni enotne in splošno priznane definicije o degradiranosti in degradiranih območij. Različne stroke in institucije, ki se posredno ali neposredno srečujejo s takšnimi območji, imajo grobe opredelitve degradiranih območjih, zato prihaja do razlik v nadzorovanju njihovega nastajanja, pri sanaciji in tudi pri načrtih za njihovo nadaljnjo rabo.

V osnovi predstavljajo degradirana območja bolj ali manj sklenjena opuščena območja, ki imajo zaradi spleta in součinkovanja različnih dejavnikov negativen vpliv na nekatere ekosisteme (zmanjševanje biotske raznovrstnosti) in človeka ter kvarijo estetski videz pokrajine. Vseeno pa lahko takšna območja pomenijo ob primerni sanaciji potencial za nadaljnjo učinkovito trajnostno rabo. Z učinkovito sanacijo teh območij bi zaustavili njihovo nadaljnjo širitev, že degradirane površine pa bi spremenili v funkcionalna zemljišča z zmanjšanimi negativnimi vplivi na okolje, vrnili pokrajini estetski videz ter tako pripomogli k razvoju lokalnih skupnosti.

Članek predstavlja povzetek študentskega raziskovalnega projekta, katerega namen je bil identificirati, inventarizirati ter geografsko ovrednotiti degradirana območja v Gorenjski, Osrednjeslovenski, Zasavski in Spodnjeposavski statistični regiji ter statistični regiji Jugovzhodna Slovenija. Kriteriji za določitev obravnavanih degradiranih območij so skladni s projektom 'Sonaravna sanacija okoljskih bremen kot trajnostno razvojna priložnost Slovenije', katerega naročnik je Služba vlade Republike Slovenije za lokalno samoupravo in regionalno politiko, nosilka pa dr. Metka Špes.

\section{METODE DELA}

V okviru študentskega raziskovalnega projekta smo se najprej seznanili s problematiko degradiranih območij v domači in tuji literaturi, kar nam je pomagalo pri njihovem definiranju, oziroma pri opredelitvi kriterijev za terensko inventarizacijo. Med marcem in majem 2011 smo na terenu popisali degradirana območja v Gorenjski, Osrednjeslovenski, Zasavski in Posavski statistični regiji ter v statistični regiji Jugovzhodna Slovenija.

Popis je potekal v treh fazah. V prvi fazi so se popisovalci seznanili z občino z vidika degradiranosti. Ta faza je obsegala pregled digitalnih ortofotografskih posnetkov, na katerih so opazne potencialne degradirane površine, pregled občinskih prostorskih načrtov ter ostale literature, neposredno povezane $\mathrm{z}$ degradiranimi območji na preučevanem območju. Druga faza je vključevala sestanke popisovalcev z občinskimi predstavniki, ki so popisovalcem povedali, katera območja v njihovi občini ustrezajo zahtevanim kriterijem degradiranosti, katera območja razumejo kot degradirana ter kakšne načrte za ravnanje s temi območji imajo. Tretja faza je zajemala pregled potencialnih degradiranih območij na terenu, kjer so se popisovalci dokončno odločili, ali območje ustreza zahtevanim kriterijem degradiranosti. Ta območja smo evidentirali ter njihove atribute (velikost, infrastrukturna opremljenost, dostopnost, idr.) vnesli v popisni list. 
Na terenu smo evidentirali le območja, kjer je dejavnost, ki je degradacijo povzročila, opuščena ali prisotna le v zmanjšanem obsegu. Popisali smo tudi degradirana območja, kjer prvotne dejavnosti ni več, je pa delno prisotna nova dejavnost. $Z$ vidika preteklih in izjemoma/omejenih obstoječih dejavnosti smo popisali le industrijska območja, rudarska območja in jalovišča, vojaška območja ter transportne in druge infrastrukturne površine in objekte. Pri velikosti degradiranih območij smo kot spodnjo mejo upoštevali en hektar.

Informacije, pridobljene na terenu ali pri strokovnih institucijah, smo umestili v digitalni sloj podatkov v Geopediji, ki prikazuje prostorsko razporeditev degradiranih območij, katerim so dodani atributi z evidenčnega lista.

\section{OSNOVNE ZNAČILNOSTI DEGRADIRANIH OBMOČIJ}

Na območju Gorenjske, Osrednjeslovenske, Zasavske in Posavske statistične regije ter statistične regije Jugovzhodna Slovenija je bilo evidentiranih in inventariziranih 88 degradiranih območij, največ (33) v Osrednjeslovenski statistični regiji. Popisanih je bilo 52 industrijskih, 14 transportnih, 9 vojaških in 8 rudarskih degradiranih območij ter 5 mešanih območij, kjer gre za kombinacijo dveh vrst degradiranosti na enem sklenjenem območju (najpogostejša je kombinacija industrijskih in transportnih degradacij). Na preučevanem območju imajo največje skupne površine degradiranih površin v občinah Trbovlje (135 ha), Kranj (66,5 ha) in Krško (52 ha). Največje sklenjeno degradirano območje je bilo evidentirano v Kamniku (podjetje KIK; 46,3 ha).

\section{Slika 1: Vrste degradiranih območij}

Figure 1: Brownfield types

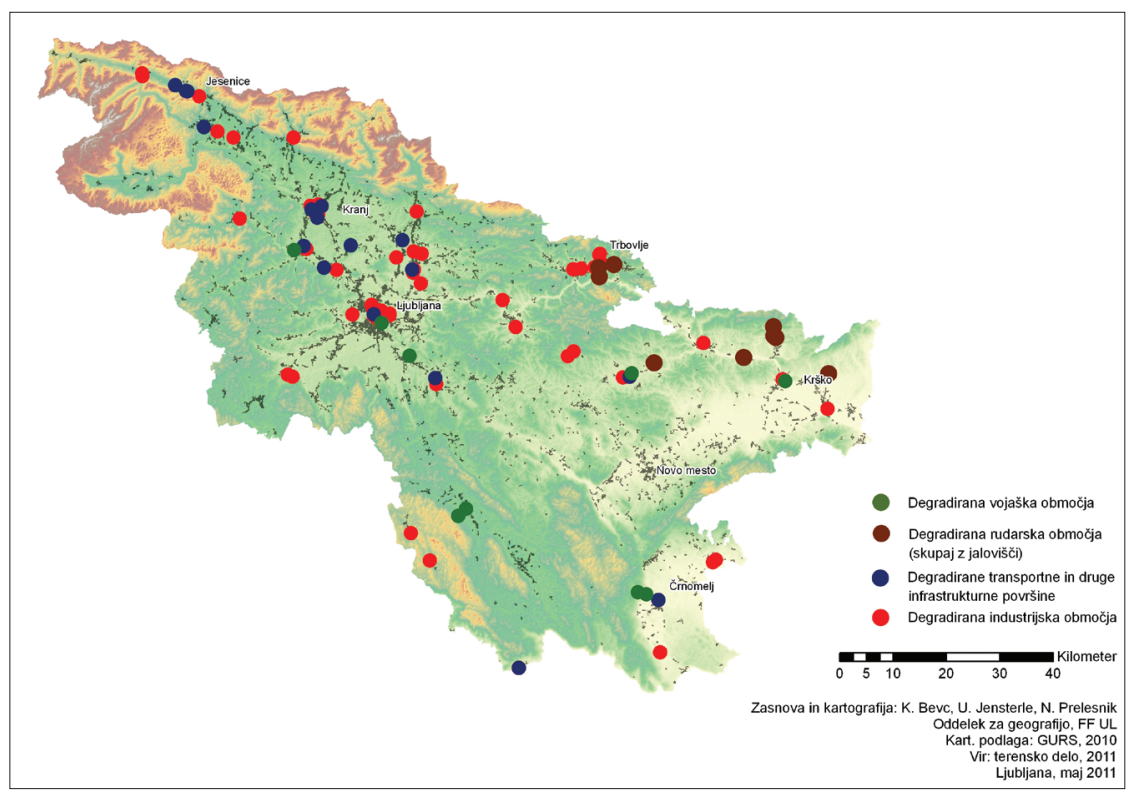




\section{GEOGRAFSKO VREDNOTENJE DEGRADIRANIH OBMOČIJ}

Pri geografskem vrednotenju degradiranih območij smo se oprli na pokrajinsko tipologijo, s pomočjo katere smo ugotovili, kakšne so lastnosti pokrajinotvornih sestavin na degradiranih območjih. Pokrajinskoekološki tipi so namreč optimalno homogeni deli pokrajine, ki se približno enako odzivajo na različne človekove vplive, se pravi, da imajo podobne nosilne sposobnosti. V ospredju so skupne značilnosti posameznih, tudi prostorsko oddaljenih delov ozemlja (Špes in sod., 2002). V strokovni literaturi je Slovenija razdeljena na 14 pokrajinskoekoloških tipov, na območju preučevanih statističnih regij pa se nahaja 10 različnih pokrajinskoekoloških tipov.

\section{Slika 2: Degradirana območja po pokrajinskoekoloških tipih}

Figure 2: Brownfields and landscape ecology types

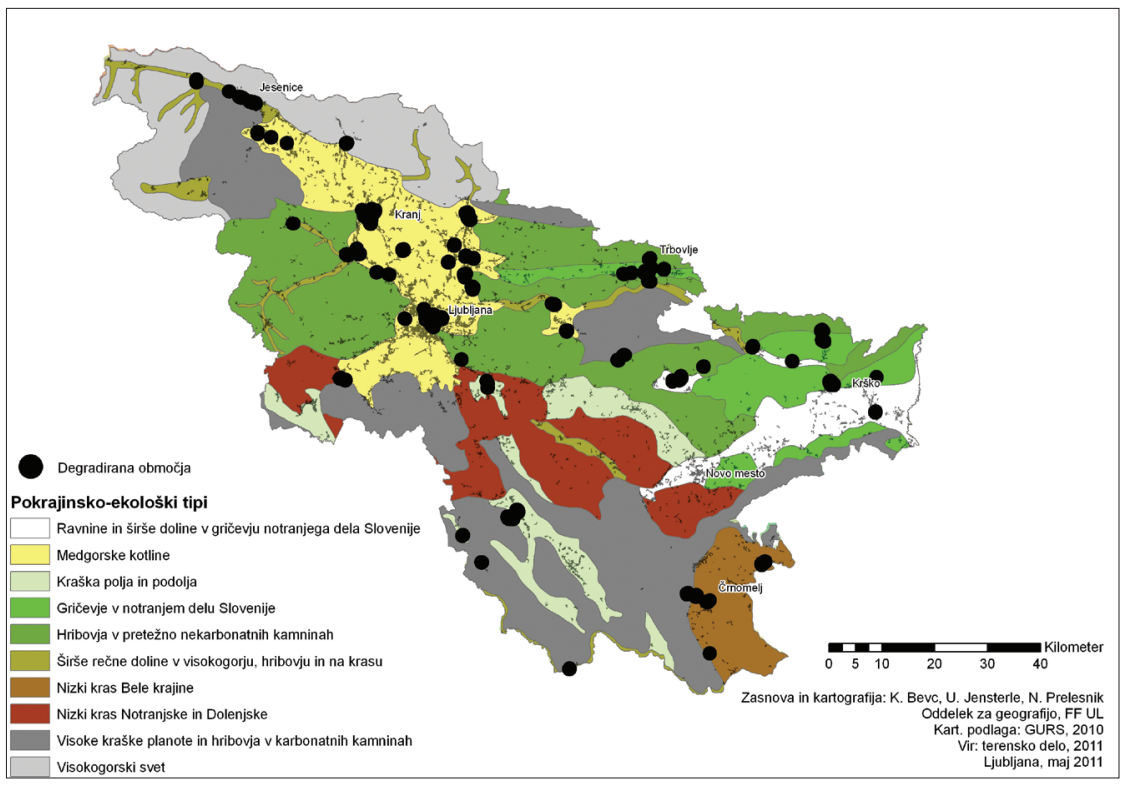

Glede na regeneracijske in nevtralizacijske lastnosti pokrajinotvornih sestavin (voda, zrak, prst...), oziroma glede na to, kako se te sestavine odzivajo na antropogene pritiske, lahko večino degradiranih območij razdelimo v dve skupini:

1. Degradirana območja na pokrajinskoekoloških tipih s slabšimi samočistilnimi sposobnosti zraka. Sem uvrščamo območja v pokrajinskoekoloških tipih Medgorske kotline, Širše rečne doline v visokogorju, hribovju in na krasu ter Ravnine in širše doline v gričevju notranjega dela Slovenije. Za to skupino pokrajinskoekoloških tipov je značilna slaba prevetrenost in zastajanje zraka, zaradi česar so njegove regeneracijske in nevtralizacijske sposobnosti zmanjšane. V tej skupini pokrajinskoeko- 
loških tipov se nahaja 60 degradiranih območij, večina na urbaniziranem območju Ljubljanske kotline (npr. območji bivše IMP in tovarne Rog v Ljubljani, Planika v Kranju, idr.). V skladu z načeli trajnostnega razvoja bi bilo pri širjenju že obstoječih ali umeščanju novih dejavnosti na degradirana območja potrebno upoštevati omejene regeneracijske in nevtralizacijske sposobnosti zraka ter smiselno načrtovati dejavnosti, ki obremenjenosti zraka ne bi povečale.

2. Degradirana območja na pokrajinskoekoloških tipih s slabšimi samočistilnimi sposobnostmi vode in prsti. Sem uvrščamo območja v pokrajinskoekoloških tipih Kraška polja in podolja, Nizki kras Bele krajine ter Visoke kraške planote in hribovja v karbonatnih kamninah. V tej skupini prevladujeta karbonatna matična podlaga ter kraški tip površja, za katerega je značilno podzemno odtekanje voda ter posledično odsotnost površinskih voda. Regeneracijske sposobnosti vode in prsti v tej skupini so zmanjšane. Na 12 degradiranih območjih v tej skupini pokrajinskoekoloških tipov (npr. Beti v Metliki, objekt pod Slivniškim vrhom v Grosuplju, nekdanji TSO Suhor v Črnomlju) bi morali načrtovati dejavnosti, ki ne bi dodatno obremenjevale prsti in vode.

Slika 3: Degradirano območje Kopitarna Sevnica (foto U. Prislan)

Figure 3: Brownfield at Kopitarna Sevnica (photo U. Prislan)

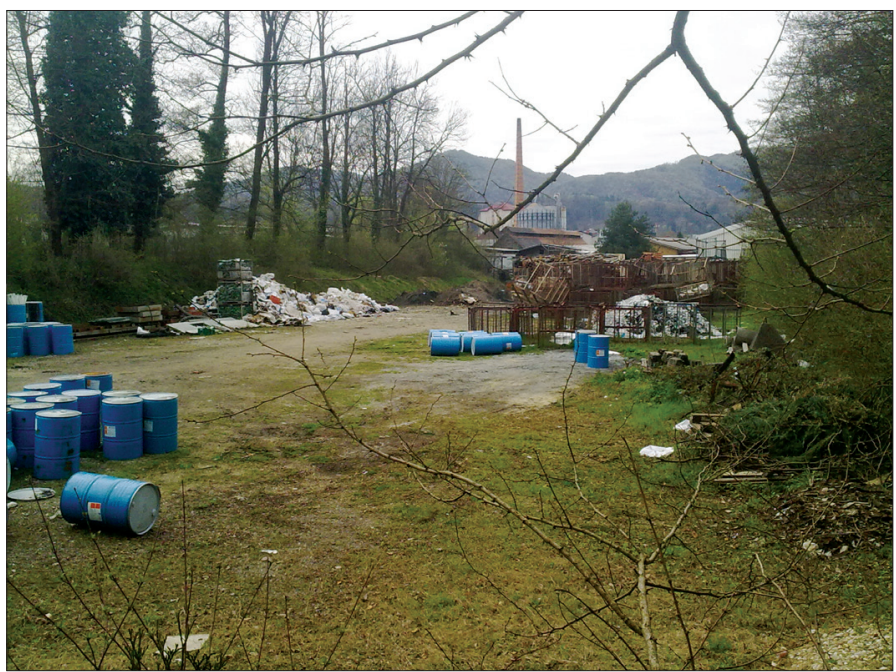

\section{DEGRADIRANA OBMOČJA NA VODOVARSTVENIH OBMOČJIH}

Vodovarstvene površine so območja vodnih teles in njihovega napajalnega območja, ki varuje vodno telo pred onesnaževanjem ali drugimi vrstami obremenjevanja. Vodnim telesom na takšnih območjih pripisujemo dolgoročni pomen za lokalni in regionalni razvoj, saj so ključnega pomena za zagotavljanje pitne vode. Izvajanje gradbenih del na takšnih 
območjih mora biti načrtovano tako, da je tveganje za onesnaževanje vodnega telesa zaradi gradnje objektov ter izvajanja gradbenih del sprejemljivo (Pravilnik o kriterijih ..., 2011).

$\mathrm{Na}$ degradiranih območjih obstaja potencialna nevarnost, da se obremenjenost vodnih teles ali njihovih napajalnih območij poveča z gradnjo objektov, staro ali neurejeno infrastrukturo, z odpadki, odplakami, skladiščenjem in prevozom nevarnih snovi.

V preučevanih statističnih regijah je bilo na vodovarstvenih območjih evidentiranih in inventariziranih 18 degradiranih območij. Največ jih je v Ljubljanski in Krški kotlini, ugotavljamo pa, da glede na vrsto še vedno prisotnih dejavnosti v glavnem ne predstavljajo neposredne grožnje vodnim telesom ali njihovim napajalnim območjem.

Potencialno grožnjo vodnim telesom predstavlja nekaj degradiranih območij tudi izven vodovarstvenih območjih:

- $\quad \mathrm{v}$ farmi prašičev $\mathrm{v}$ Ihanu kljub čistilni napravi prihaja do izcejanja odpadnih voda $\mathrm{v}$ Kamniško Bistrico;

- na degradiranem območju Planike v Kranju na deponiji gradbenega materiala v izkopni jami zastaja onesnažena voda, ki nato ponikne $\mathrm{v}$ tla in predstavlja potencialno grožnjo podtalnici (slika 4).

Slika 4: Deponija gradbenega materiala pri Planiki v Kranju (foto A. Draksler) Figure 4: Building waste disposal at Planika in Kranj (photo A. Draksler)

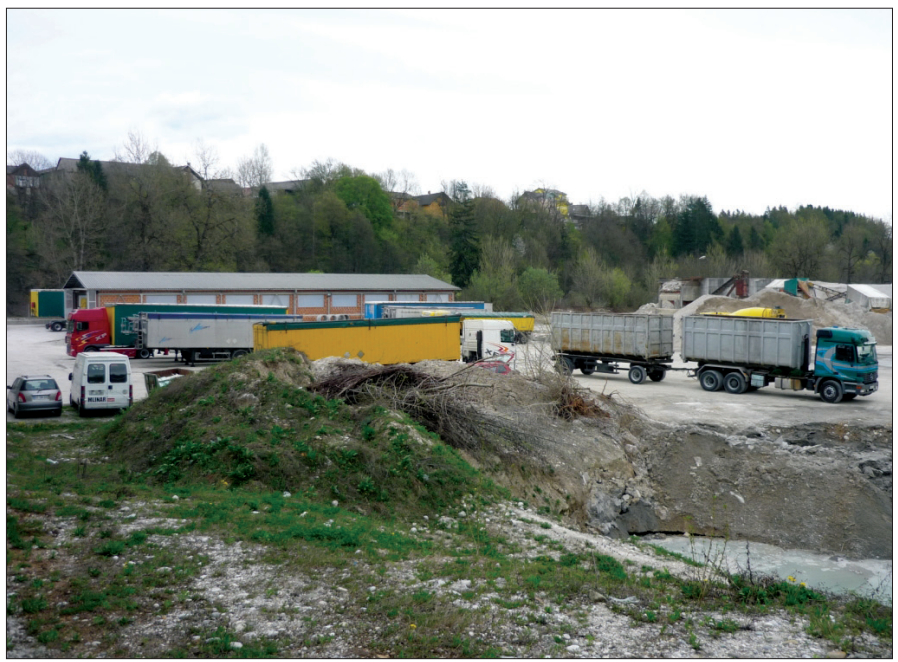

\section{DEGRADIRANA OBMOČJA NA ZAVAROVANIH OBMOČJIH IN OBMOČJIH NATURE 2000}

Natura 2000 je evropsko omrežje posebnih varstvenih območij, ki so jih določile članice Evropske unije. Njen glavni cilj je ohraniti biotsko raznovrstnost za prihodnje rodove. Območja Nature 2000 zajemajo 36 \% slovenskega ozemlja. Določena so na 
podlagi direktive o pticah in habitatne direktive. Obe direktivi podpirata trajnostni razvoj in ne izključujeta človekovih dejavnosti, ki ne ogrožajo narave (Zavarovana območja, 2011).

Zavarovana območja spadajo med ukrepe varstva narave in so najpomembnejši inštrument varstva biotske raznovrstnosti. Ponašajo se s številnimi naravnimi, kulturnimi in duhovnimi vrednotami (Plut, 2008). Zakon o ohranjanju narave pri nas opredeljuje širša in ožja zavarovana območja. Zavarovanih je 12,6 \% površine Slovenije, skupaj z Naturo 2000 pa ta območja obsegajo 40 \% površja Slovenije (Zavarovana območja, 2011).

V omrežje Natura 2000 je vključenega skoraj 55 \% preučevanega območja, zavarovana območja pa obsegajo več kot $10 \%$ tega območja. Ker se območja Nature 2000 in zavarovana območja na 7 \% površin prekrivajo, oboja skupaj pokrivajo 58 \% preučevanega območja.

Preglednica 1: Razmestitev in število evidentiranih degradiranih območij na zavarovanih območjih

Table 1: Locations and number of recorded brownfield sites in protected areas

\begin{tabular}{|l|c|}
\hline Razmestitev evidentiranih degradiranih območij & $\begin{array}{c}\text { Stevilo degradiranih } \\
\text { območij }\end{array}$ \\
\hline Evidentirana degradirana območja na območju Nature 2000 & 3 \\
\hline Evidentirana degradirana območja, ki mejijo na območje Nature 2000 & 4 \\
\hline Evidentirana degradirana območja, ki mejijo na zavarovano območje & 1 \\
\hline $\begin{array}{l}\text { Evidentirana degradirana območja, ki z manjšim delom segajo na zavarovano } \\
\text { območje }\end{array}$ & 1 \\
\hline
\end{tabular}

Med degradiranimi območji iz preglednice 1 prevladujejo industrijska, zgolj dve degradirani območji sta vojaški. Precej se razlikujejo po stopnji opuščenosti: na štirih je dejavnost, ki je degradacijo povzročila, opuščena, na štirih je tovrstna dejavnost še delno prisotna, na enem degradiranem območju pa že poteka nova dejavnost.

S pomočjo podatkov s terena smo prišli do zaključka, da osem od devetih degradiranih območij ne predstavlja potencialne grožnje okolju. Okoljsko sporno je le eno degradirano območje, in sicer Gospodarska cona Kostel Pirče, v kateri se nahaja podjetje, ki pri proizvodnji uporablja strupene lake in barve, dejavnost pa je tudi precej hrupna.

Evidentirana degradirana območja so tako v občinski kot zasebni lasti. V primeru slednjih občine nimajo izdelanih načrtov njihove bodoče rabe, za degradirana območja v občinski lasti pa načrti praviloma obstajajo. Ponekod nameravajo celotna degradirana območja nameniti eni dejavnosti, drugje pa jih razdeliti na manjša območja in nanje umestiti različne dejavnosti. Na degradiranih območjih nameravajo širiti obstoječe dejavnosti, graditi stanovanja, nanje usmerjati prehrambeno industrijo, obrtno-storitvene dejavnosti, ekoturizem, urediti zelene površine, postaviti sončne elektrarne ali čistilne naprave.

Reševanja problematike degradiranih območij na območjih z veliko ekološko, biotsko in pokrajinsko vrednostjo, kakršna so območje Nature 2000 in zavarovana območja, se je možno lotiti na več načinov. 
Poglavitnega pomena je zavedanje, da je potrebno ta degradirana območja zaradi izjemnega naravnega in kulturnega pomena zavarovanih območij čim prej sanirati v skladu z načeli trajnostnega razvoja. Dejavnostim, ki se nahajajo na navedenih degradiranih območjih in s svojim delovanjem ogrožajo okolje, bi bilo potrebno preprečiti širjenje, oziroma jih premestiti na primernejšo lokacijo ali vsaj izvesti določene preventivne ukrepe.

Kot primer navajamo manjši obrat kovinske industrije na degradiranem območju Gospodarska cona Kostel Pirče, ki bi ga bilo smiselno namestiti izven območja habitatov divjih zveri, oziroma vsaj izvesti določene ukrepe, npr. postavitev protihrupnih ograj in uporabo ekoloških barv in lakov. Občina Kostel ima z Gospodarsko cono Kostel Pirče popolnoma drugačne in okoljsko precej sporne načrte, saj namerava na degradiranem območju širiti kovinsko industrijo.

V degradirana območja, ki se nahajajo znotraj Nature 2000, oziroma na zavarovanih območjih ali pa mejijo nanje, bi bilo najprimerneje umestiti okolju prijazne dejavnosti, kot so ekoturizem, rekreacijske in športne dejavnosti ter stanovanjska naselja, dom upokojencev ali izobraževalne ustanove za pasivno gradnjo. Ustrezna bi bila tudi sprememba dejanske rabe zemljišča v zelene površine. Osnovni ukrep ohranjanja in varovanja pa je vsekakor preprečevanje nastajanja novih degradiranih območij znotraj zavarovanih območij in območij Nature 2000.

Slika 5: Degradirana območja na zavarovanih območjih in območjih Nature 2000

Figure 5: Brownfield sites in protected areas and areas of Natura 2000

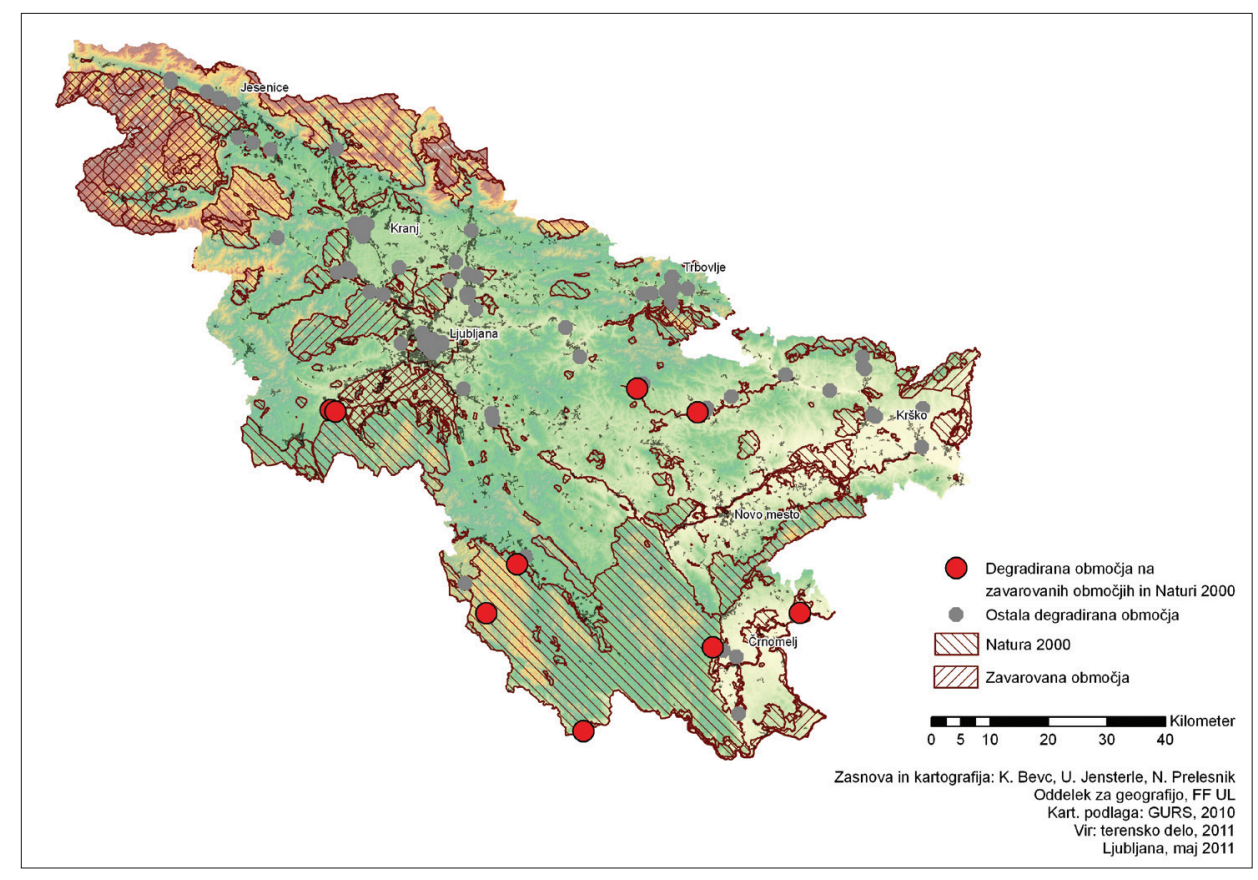




\section{OSTALA DEGRADIRANA OBMOČJA}

Kot poglavitni problem številnih slovenskih občin, ki smo jih vključili v raziskovalni projekt, se je izkazalo pomanjkanje strokovnjakov, ki bi sproti, celovito in kakovostno reševali problematiko degradiranih območij. Opazen je tudi razkorak med občinami pri opredeljevanju degradiranosti in degradiranih območjih. Zato je tudi pri razgovorih na občinah prihajalo do razlik v kakovosti podajanja informacij in razumevanju preučevane problematike, čeprav se večina občin srečuje s podobnimi problemi, povezanimi z degradacijo okolja.

Poleg degradiranih območij, ki so ustrezala našim izbranim kriterijem, je večina občin izpostavila še druga območja, ki bi jih ravno tako uvrstili med degradirana in so zelo problematična, oziroma potrebna sanacije. Med slednjimi so najpogosteje omenjeni kamnolomi, gramoznice, peskokopi, divja odlagališča odpadkov, opuščeni hlevi in farme ter deponije komunalnih odpadkov. Poleg teh so izpostavili še glinokope, romska naselja, ribogojnico, kopališče, smučišče, športno igrišče, zapuščene stanovanjske in trgovske objekte, vadbeno strelišče policije in opuščen hipodrom.

Kamnolomi predstavljajo najbolj množičen pojav degradacije okolja, ki ni bil zajet v raziskovalnem projektu. Nekateri so že sanirani, ponekod so sanacije v teku. Med nesaniranimi so nekateri kamnolomi popolnoma opuščeni in prepuščeni sukcesiji, nekatere zasebniki uporabljajo za različne prireditve, ali pa so vanje nezakonito že umestili nove dejavnosti. Nekatere občine vidijo v opuščenih kamnolomih tudi velik potencial za raznovrstne dejavnosti. V občini Dobrepolje naj bi npr. na območju kamnoloma predvidoma postavili kamp, kamnolom v občini Trzin predstavlja potencialno območje za umestitev novega pokopališča, v občini Kostel nameravajo na območju kamnoloma postaviti sončno elektrarno za potrebe bližnje vasi.

Hlevi in živinorejske farme so razmeroma obsežna degradirana območja, povečini opuščena in že tudi propadajo. Izpostavljamo problem farm v občini Kočevje, ki s pomočjo subvencij še vedno delujejo. Če bi prišlo do njihovega izpada, je možnost propada farm velika in nastala bi nova obsežna degradirana območja. Podobni problemi nastanka potencialnih novih degradiranih območij zaradi propada obstoječih dejavnosti pretijo tudi drugim občinam.

Zanimiv je tudi primer zapuščenih stanovanjskih objektov, s katerim se soočajo občine na demografsko ogroženih območjih.

Na območju nekaterih nekdanjih glinokopov so nastala jezera, ki so danes opredeljena kot naravni biotop. Občina Straža namerava na takšnem območju v prihodnosti speljati učno pot.

Večini občinam je v interesu ureditev degradiranih območij, vendar pa se pri reševanju problematike degradiranih območij srečujejo z ovirami in izzivi, kot so na primer (za ponazoritev navajamo nekaj primerov):

- Območje vojaškega skladišča Ugar naj bi bilo po oceni občine Ribnica deloma v najemu, najemnik pa naj bi ga povezal z bližnjim opuščenim kamnolomom in mu spremenil namembnost za potrebe ekoturizma. Po drugih neuradnih virih naj bi bilo celotno območje v lasti Slovenske vojske in ni možnih nikakršnih sprememb. 
Natančnejši terenski popis območja nam je preprečila ograja. Na podobne težave smo naleteli tudi pri popisu degradiranega vojaškega območja Naklo.

- Problemi so tudi z lastništvom degradiranih območij. Nekatera so v državni ali zasebni lasti, postopki predaje oziroma prodaje občinam pa so zelo dolgotrajni. Zlasti kadar je degradirano območje v posesti večjega števila lastnikov, je izvedba sanacije zelo otežena. Občina Kočevje se npr. še vedno sooča z zapletenimi postopki v zvezi z lastnino kočevskih Nemcev.

- Nekatere občine, tudi občina Žužemberk, izražajo nezadovoljstvo zaradi dejstva, da so posamezna degradirana območja vključena v območja Nature 2000, oziroma sodijo v kulturno dediščino. Sanacija teh območij naj bi bila zaradi s tem povezanih omejitev in usmeritev dražja, dolgotrajnejša ali celo onemogočena.

\section{SKLEP}

Degradirana območja so v Sloveniji zelo aktualna in pereča, a so obenem potencialna območja za umeščanje novih dejavnosti. S to problematiko smo se soočili tudi študentje geografije, ko smo izvajali samostojni študentski projekt v okviru usmeritvenega predmeta Varstvo geografskega okolja. Ugotovili smo, da občine različno rešujejo in ocenjujejo probleme degradiranih območij. Prav tako se razlikujejo tudi pri razumevanju teh površin kot potencialov za umeščanje novih dejavnosti, tudi tistih, ki so skladne s trajnostnimi načeli.

Ugotavljamo, da občine različno opredeljujejo degradirana območja (nekatere občine npr. uvrščajo vojaška območja med degradirana, druge ne). Večje občine slabše poznajo svoja degradirana območja in se z reševanjem te problematike soočajo manj učinkovito kot manjše občine. Občine z manjšim proračunom težje rešujejo problematiko degradiranih območij.

V našem raziskovalnem projektu smo upoštevali kriterije za določitev degradiranih območij, ki ne vključujejo vseh vrst in tipov degradacije. Evidenco degradiranih območij, ki je nastala kot rezultat našega dela, bi bilo v prihodnje moč dopolniti z ostalimi degradiranimi območji (območja, manjša od enega hektarja, kamnolomi, ilegalna odlagališča odpadkov, idr.).

Reševanje problematike degradiranega okolja je dolgotrajen in zapleten postopek, odvisen od številnih dejavnikov. Pri njegovem izvajanju se poslužujemo različnih, bolj ali manj ustreznih metod, ki pa vse temeljijo na dobri evidenci. V članku je opisan primer evidentiranja degradiranih območij, ki so ostanek industrijske, vojaške, rudarske ali transportne dejavnosti. V nadaljevanju je potrebno ob podrobni analizi gospodarskih, okoljskih in drugih dejavnikov predvideti ustrezne sanacijske ukrepe, ki bodo sledili načelom trajnostnega razvoja, preprečiti širjenje že obstoječih degradiranih območij, pa tudi preprečiti nastajanje novih. Posebno pozornost bi morali nameniti degradiranim območjem, ki zaradi lege in vrste degradacije že sedaj prekomerno obremenjujejo okolje in/ali so na območju, kjer je občutljivost posameznih pokrajinskih sestavin povečana. 


\section{Viri in literatura}

Belec, V., Bembič, M., Bevc, K., Bužinel, S., Cerar, G., Cvahte, A., Černič, B., Černjavič, M., Dokler, T., Donko, A., Draksler, A., Dremšak, R., Ferko, P., Gabršček, P., Groznik, M., Hočevar, M., Jakovac, N., Jensterle, U., Justin, M., Klemenčič, I., Klinc, M., Kolar, B., Kolar-Erat, T., Lavrič, P., Loparnik, Z., Miočinovič, N., Mljač, M., Prelesnik, N., Prislan, U., Rodman, N., Ropret, D., Snoj, L., Sterle, N., Špehar, S., Zgonc, L., Žigon, D., 2011. Inventarizacija degradiranih območij v Gorenjski, Osrednjeslovenski, Zasavski, Spodnjeposavski statistični regiji in Statistični regiji Jugovzhodna Slovenija. Elaborat. Ljubljana, Filozofska fakulteta, Oddelek za geografijo, 57 str.

O Naturi 2000. URL: http://www.natura2000.gov.si/index.php?id=18 (Citirano 22. 7. 2011).

Plut, D., 2008. Trajnostni razvoj varovanih območij - celostni pristop in aktivna vloga države. Trajnostno gospodarjenje v varovanih območjih z vidika doseganja skladnejšega regionalnega razvoja. Končno poročilo. Ljubljana, 188 str.

Pravilnik o kriterijih za določitev vodovarstvenega območja. Ministrstvo za okolje, prostor in energijo. URL: http:/www.mop.gov.si/fileadmin/mop.gov.si/pageuploads/zakonodaja/ okolje/voda/dolocitev_vodovarstvenih_obmocij.pdf (Citirano 22. 7. 2011).

Špes, M., Cigale, D., Lampič, B., Natek, K., Plut, D., Smrekar, A., 2002. Študija ranljivosti okolja (metodologija in aplikacija). Geographica Slovenica, 35, 1-2, str. 1-150. Ljubljana.

Zavarovana območja. ARSO. URL: http://www.arso.gov.si/narava/zavarovana\%20 obmo\%C4\%8Dja/ (Citirano 22. 5. 2011).

\section{GEOGRAPHICAL EVALUATION OF BROWNFIELDS IN SELECTED STATISTICAL REGIONS}

\section{Summary}

The article is based on the research project on brownfields which was carried out by students of geography as a part of our study program. The work was focused on brownfields in five Slovenian statistical regions (NUTS 3 level): Gorenjska, Osrednjeslovenska, Spodnjeposavska, Zasavska and Jugovzhodna Slovenija.

Brownfields represent mostly abandoned areas that became degraded and abandoned due to combination and interaction of different factors, causing a negative impact on some ecosystems (biodiversity loss) and on the aesthetic appearance of the landscape. Our goals were to identify brownfields in selected NUTS 3 regions, make an inventory and geographically evaluate identified sites. We were interested in areas where degradation had its origin in an industrial, military, transport or mining background. Only the brownfields with an area larger than one hectare were selected.

Brownfields were identified through analysis of orthophoto images and consultations with municipalities' representatives. In selected regions, 88 brownfields were identified, most of them $(66 \%)$ having an industrial origin. Geographical evaluation has singled out brownfields which could represent a threat to the environment and to the society. We 
have pointed out and analyzed brownfields which are located on protected areas or are part of the Natura 2000 ecological network, and sites located on water protected areas. Cross referencing the brownfields locations with a landscape ecology map has shown which brownfields are located on karst terrain and could represent a potential threat for water and soil contamination, and which are located in basins and valleys and could represent a potential threat for air contamination. The paper also presents findings on other degraded areas which were not included in inventory, such as quarries, gravel pits, illegal waste dumps, farms, etc.

Solving a problem of degradated environment is a long and complex process which depends on many factors. Its implementation relies on methods with varying suitability, but all are based on good records. A thorough analysis of economical, environmental and other factors is necessary to plan appropriate remedial actions which would follow the principles of sustainable development.

\section{(Translated by the authors)}

Članek je nastal v okviru samostojnega raziskovalnega projekta 'Sonaravna sanacija okoljskih bremen kot trajnostno razvojna priložnost Slovenije', ki se je izvajal pri usmeritvenem predmetu Varstvo geografskega okolja v povezavi z delom Raziskovalnega centra Oddelka za geografijo Filozofske fakultete. Projekt je nastal pod mentorstvom dr. Metke Špes, doc. dr. Barbare Lampič in doc. dr. Irene Mrak, izvajalci projekta pa so bili študenti 4. letnika geografije: Vanja Belec, Maks Bembič, Kristjan Bevc, Sanja Bužinel, Gašper Cerar, Anja Cvahte, Barbara Černič, Mateja Černjavič, Tit Dokler, Anja Donko, Andrej Draksler, Robert Dremšak, Petra Ferko, Petra Gabršček, Maja Groznik, Mina Hočevar, Nina Jakovac, Urban Jensterle, Miha Justin, Ivan Klemenčič, Matej Klinc, Boštjan Kolar, Tim Kolar-Erat, Petra Lavrič, Zala Loparnik, Nina Miočinovič, Mirjana Mljač, Nastja Prelesnik, Urša Prislan, Nastja Rodman, Dunja Ropret, Luka Snoj, Nina Strle, Simona Špehar, Lara Zgonc in Domen Žigon. 